WellBeing International

WBI Studies Repository

1985

\title{
Alternatives to Aversive Procedures with Animals in the Psychology Teaching Setting
}

Jeffrey A. Kelly

University of Mississippi Medical Center

Follow this and additional works at: https://www.wellbeingintlstudiesrepository.org/acwp_arte

Part of the Bioethics and Medical Ethics Commons, Laboratory and Basic Science Research Commons, and the Other Psychiatry and Psychology Commons

\section{Recommended Citation}

Kelly, J.A. (1985). Alternatives to aversive procedures with animals in the psychology teaching setting. In M.W. Fox \& L.D. Mickley (Eds.), Advances in animal welfare science 1985/86 (pp. 165-184). Washington, DC: The Humane Society of the United States.

This material is brought to you for free and open access by WellBeing International. It has been accepted for inclusion by an authorized administrator of the WBI Studies Repository. For more information, please contact wbisr-info@wellbeingintl.org.

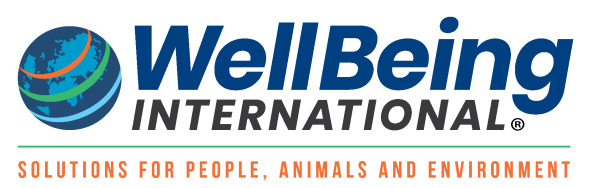




\title{
ALTERNATIVES TO AVERSIVE PROCEDURES WITH ANIMALS IN THE PSYCHOLOGY TEACHING SETTING*
}

\author{
Jeffrey A. Kelly \\ Department of Psychiatry and Human Behavior \\ University of Mississippi Medical Center \\ 2500 N. State Street \\ Jackson, MS 39216
}

\section{Introduction}

Every college undergraduate learns in his or her first introductory course that the aims of scientific psychology are understanding, explaining, and predicting behavior. How students are taught about behavior varies depending on the area of psychology involved. But within some major psychology subfields-behavior analysis, learning, experimental, and physiological psychology - teaching students about behavior often means instruction and observation in animal behavior. In some cases, students are asked to study the principles of animal behavior for their own sake. More commonly, however, animals are used in teaching or laboratory settings because they are assumed to be models which serve as approximations for analogous behavior in humans.

The treatment of research animals by behavioral scientists has received substantial and increasing scrutiny by both the public and professionals who are concerned about animal welfare. The principle focus for most of this attention has been the treatment of experimental animal subjects in biomedical or behavioral research studies and, to a lesser degree, those animals subjected to toxicity and consumer products testing. Much less attention has been directed to the welfare of animals used in teaching settings. It is unclear how many animals are used

Portions of this paper were presented to the Annual Meeting of the American Psychological Association, August, 1984 in Toronto. 
each year in undergraduate and graduate psychology department teaching laboratories, but the number appears very substantial given that most colleges and universities have animal laboratories; most use animals extensively in such courses as learning, behavior analysis, and experimental and physiological psychology; and most encourage advanced students to conduct independent projects primarily for their educational value.

While concern for animal welfare in behavioral research, biomedical research, and toxicity testing certainly demands attention, reducing the pain and suffering of animals used in teaching may be more easily attained than accomplishing that same end in some other contexts. As we will see, this is because there are alternatives in instructional settings for reducing the number of experimental animals used, for reducing their suffering, and for replacing the use of animals in aversive demonstration without compromising educational objects (see Russell and Burch 1959). Further, because no new scientific knowledge is generally gained in teaching demonstrations, there is less justification for permitting pain and distress to animals. As a result, an aversive procedure defensible in a critical research study might well be improper to use in a teaching demonstration.

In this paper, we will consider the treatment of laboratory animals in psychology instruction and will focus on practical alternatives to traditional practices that cause pain and distress to animals. While the discussion will draw on psychology for examples, many of the issues apply equally to the instruction of students in other courses of study, including medicine, veterinary medicine, biology, and physiology.

\section{Animals, Ethics, and Psychology Teaching}

Some psychological experiments employing animals pose few ethical concerns because the studies do not involve aversive conditions. Behavioral observation studies, naturalistic observations that do not interfere with animals' normal behavior, and conditioning studies that do not entail aversive procedures or the induction of severe deprivation states (e.g., water, food, social, or sensory deprivation) are relatively free of ethical concerns, subject to certain qualifications. The qualifications chiefly concern whether the animals are housed and maintained with adequate consideration of their physical, social, and emotional needs, and whether induced deprivation states are sufficiently mild so as to allow students to study motivation without creating distress to the animal. Although these qualifications sound straightforward, in fact they involve rather complex issues. For example, a teaching demonstration of positive reinforcement-i.e., showing students that a rat will learn to bar press for food on some schedule - is not an ethically prob- 
lematic procedure on the surface. However, how long that rat is fooddeprived before the demonstration begins can determine whether the teaching demonstration is actually humane. While investigators are recognizing that the severity of food, water, or other need deprivation is an ethical issue (Segal 1982) and, by inference, that past demonstrations have often used overly harsh deprivation levels, we know little about the point at which deprivation becomes inhumane and unnecessarily severe.

In similar fashion, there is a growing recognition that the conditions under which animals are maintained involve issues which extend well beyond feeding and watering the animal, and keeping its cage clean (Lockwood 1984). Animals have broader social and emotional needs that must also be taken into account in their housing. While an instructional procedure may involve no aversive conditions at all, if the animal is housed in a way that neglects its needs for environmental stimulation, the project is ethically troublesome. While there is a considerable literature documenting the social/emotional needs of various higher animals, it is rare for animal housing facilities to take these needs into account.

Ethical issues become even more pronounced when students are asked to perform procedures that clearly cause pain to animals. The kinds of aversive procedures to which animals are subjected in psychology teaching laboratories are, unfortunately, wide and varied. Classical conditioning with aversive stimuli; employing learned helplessness analogue paradigms; administering drugs; surgically ablating or lesioning; inserting and implanting invasive measurement instruments; and invasively altering sensory capabilities are aversive procedures that students commonly observe or perform on living animals.

Proponents of allowing (or requiring) students to learn about behavior by conducting such aversive exercises defend the practice on several grounds. Their arguments fall into several categories and include: (1) the conduct of animal studies, including those which cause pain, is necessary to train scientists; (2) there is no acceptable alternative to "hands-on" experimentation; (3) aversive procedures with animals represent one of the few ways to demonstrate the effects of certain behavioral phenomena; and (4) teaching demonstrations with animals already have sufficient controls to ensure the welfare of animal subjects. Let us consider these arguments and existing alternatives to them.

\section{Animal Welfare and Student Welfare}

The usual first focus of our ethical attention when animals are subjected to aversive procedures is on the welfare of the animal. That is, of course, an appropriate focus when animals are shocked, ablated, 
lesioned, operated upon, or otherwise caused pain. But it is also appropriate to inquire into the potentially negative effects to students who are asked to watch or perform such procedures.

A substantial body of research demonstrates that exposure to violence or other aversive experience gradually leads to densensitization, numbing, and an emotional acceptance of that experience. For example, persons shown films of violence or bloody human battle exhibit fairly rapid attitudinal shifts towards acceptance and toleration of violence (Thomas et al. 1977). There is no reason to think that psychologists or psychology students do not experience the same attitudinal shifts in our laboratories and classrooms. By exposing students to animal pain, or by accustoming students to causing pain to animals, we may be desensitizing them to the fact that they are hurting living beings and we may inadvertently be promoting students' tolerance or acceptance of inhumaneness. Rollin (1981), for example, describes an incident in which a student asked what should be done with some rats at the end of a teaching experiment. The student's professor had the young man watch as the professor held the rat and rapped its head against the side of a table, breaking the animal's neck. The student was taken aback by the sight and said so. The professor, according to Rollin, responded by coldly suggesting that the young man "might not be cut out to be a psychologist" if he were going to be so sensitive.

In this incident, we can identify several desensitizing factors at work. First, as the student continues his lab work, he will become emotionally desensitized to events that he formerly found troublesome. As students become used, not just to killing animals in a violent way, but also shocking, invading, operating on or otherwise maiming them, the emotional impact of doing so is gradually lessened until those actions become commonplace and emotionally unarousing.

Moreover, the social influence of a professor legitimizing, modeling, and instructing a student to perform aversive procedures is also powerful and likely to produce student compliance. Quite a number of years ago, Milgram (1963) demonstrated that professorial influence and authorization were sufficient to cause students to personally administer what they thought were extremely painful electric shocks to another person. When a student is trying to be "scientific," hoping to please a professor, and when the recipient of pain-infliction is an animal rather than the perceived human in Milgram's study, shifts towards inhumaneness in student attitudes, values, and ethical sensitivities are even more likely.

We often become professionally indignant when the media publishes photographs of research animals immobilized, implanted, maimed, and in pain. The public is startled, shocked, and often upset when they see such photographs. As psychologists, our response is often to dismiss public reaction by saying something like, "They really don't understand 
what we are doing," or "They haven't been exposed to the methods and benefits of this research." However, what we may really be witnessing is a discrepancy between professionals who have desensitized themselves to an animal's pain and a public which is appropriately sensitive to animal distress.

In our role as educators, should we try to desensitize students to pain? Should we be reassuring students in our undergraduate and graduate labs that it is perfectly acceptable for them to shock or experimentally operate on animals just so they can see some known behavioral phenomenon firsthand? That is often what we do, and often we do it without much thought at all. The implicit messages that we may inadvertently be teaching students are that "Cruelty in the name of science is okay,"* "It's only a rat and it will be dead next week anyway," or, even worse, "The end justifies the means."

Thus, the issue of animal welfare in the teaching setting also raises the issue of student welfare. If teaching practices do reduce humane sensitivity, we may also be at risk for producing students who have become dulled not only to pain, but to empathy and observational acuity as well. Within the medical profession, observers have pointed out that all too many physicians have outstanding technical skills but appear desensitized to, and emotionally distanced from, their patients (Maddison 1978). They suggest that medical training directly fosters this problem by promoting the view that living beings are objects to be mechanistically studied, observed, or treated with as little emotional involvement as possible.

In psychology, we must be especially concerned about teaching practices that may hinder a student's capacity to develop characteristics such as accurate empathy, sensitivity, and humaneness, since these characteristics appear to be necessary to effective clinical practice (Truax et al. 1966). Because many students in undergraduate and graduate psychology labs will one day work with people, we should be working to increase sensitivity and humaneness, rather than destroying these characteristics.

Even within the animal laboratory setting, aversive procedures with animals may blunt students' observational and cognitive skills. High emotional arousal - anxiety - disrupts fine-grained observational acuity, cognitive performance, problem-solving, and recall (Janis and Mann 1977). If a student is upset by an aversive teaching exercise, that student's ability to learn from the demonstration is also lessened. On the other hand, if a student is desensitized to, and unaffected by, an

*The message that cruelty in the name of science is somehow different than cruelty to animals on a city street has been conveyed not only to students but also, evidently, to legislators. Many ordinances specifically exempt certain activities in universities and research facilities from prosecution under local anti-cruelty statutes. 
animal's pain, that student may actually become a less skilled observer of behavior. Reese (1984) has pointed out that by allowing students to somehow "pretend" that animals are inanimate or insensitive objects a precursor, it would seem, to intentionally hurting them-we encourage students to misperceive and distort other aspects of what they observe. In doing so, the objectivity on which good science relies is undermined.

Finally, in a broader view, we live in a world that seems too often characterized by insensitivity, inhumanity, and a lack of concern and empathy for other beings. The extent to which sensitivity to animal welfare facilitates sensitivity to human welfare is not yet well-established, but such a linkage is both plausible and probable. From this broader perspective, behavioral scientists especially should be addressing ways to increase students' humane sensitivity and should never try to extinguish it.

\section{Alternatives to Aversive Demonstrations}

If we accept as desirable the goal of reducing the number of animals subjected to pain in order to educate students, both for the animals' sake and the students' sake, the next task becomes one of developing instructional alternatives. To see how alternatives can be developed, let us first consider what we try to accomplish when teaching psychology, including experimentally-oriented classes.

In most psychology course work, we want students to gain knowledge, information, and the ability to form hypotheses, rather than personal skill or expertise in using a technique. For example, we want students to understand the key principles of conditioning and learning, not to learn how to operate a conditioning chamber or to shock rats. We want students to understand and appreciate principles of neurological functioning and the physiological bases for behavior, not to master the skill of operating on an animal.

Is it really necessary for students to shock animals in order to learn the fundamentals of avoidance conditioning or classical conditioning? Must students implant electrodes or ablate and lesion animals to learn principles of physiological psychology? Almost certainly not, especially if they are undergraduate or graduate students who are not preparing for careers in physiological research. Students studying psychology need to understand and appreciate the principles of behavior; the vast majority will never need to master specific techniques that cause pain to animals. In most teaching demonstrations and student practice with animals, the use of the animal is but a means to an end - knowledge - and there may be better and certainly more humane ways to reach that end. 
What are some methods for teaching students behavioral principles that do not entail aversive procedures with animals? Since there is already an enormous data base on most behavioral phenomena, asking students to read, listen, and think critically about behavioral principles is still a viable way to teach. Students can study and discuss phenomena like aversive classical conditioning, sensation/perception processes, and neurological functioning comprehensively, accurately, and at a higher conceptual level than they could while performing isolated laboratory experiments with animals in these areas. Computers can be used to present graphic, lively, visual portrayals to illustrate physiological/ neurological processes more clearly than experiments using living animals without sacrificing interest value. There are also known laboratory alternatives to some aversive procedures. For example, students can conduct classical conditioning studies with paradigms using unconditioned positive rather than aversive stimuli, a fact psychologists sometimes forget. Even within the operant literature, students can choose among many different methods to reduce behavior which do not involve punishment or aversive stimuli (see Reese 1984).

On those rare occasions when a pain-causing phenomenon must really be seen to be understood, a teacher can videotape the procedure once with a single animal and show the tape on all subsequent occasions rather than demonstrate the phenomenon "live" or ask students to perform it on many animals again and again, semester after semester. Observation of a videotape, in lieu of actual practice of an aversive technique, may carry a number of teaching advantages. Tapes can focus on a specific feature of interest, tapes can be replayed by the student and re-observed,and a skillfully-made videotape may prove educationally superior to clumsy, hands-on practice with a living animal. Branch and his colleagues (Branch et al. 1984) have successfully used interactive videotapes to replace certain live animal demonstrations in veterinary education; similar applications can be made in areas such as psychology, medical education, and physiology.

Those who defend the status quo of allowing students to conduct aversive procedures with animals typically cite several justifications for the practice. These justifications involve the long tradition of student experimentation with animals, a belief that students cannot otherwise acquire observational/experimental skills, and the view that students must personally conduct aversive experiments in order to fully understand the phenomenon they are studying.

With respect to the tradition argument, it requires only cursory reflection to see that many widely-accepted traditions from the past today seem crude, archaic, and curious. It used to be accepted tradition to sacrifice animals and humans to the gods, to burn "witches" at the stake, and to drain suspect humors from the bodies of emotionally-disturbed 
persons. Gradually, people realized that these traditions were unnecessary, invalid or inhumane, and they were abandoned. In an era of enlightened attitudes towards animal welfare, the practice of allowing students to hurt animals in order to see some phenomenon that is already perfectly well-known seems equally anachronistic. The practices that guided student training in the past are not necessarily those that need to be followed in the present, especially if we take seriously our professed professional commitment to improving animal welfare.

With respect to the argument that students cannot acquire observational and hypothesis-forming skills without conducting animal experiments, two points can be raised. First, it is possible for students to conduct many animal behavior projects in a humane, ethical manner; it is projects which cause pain to animals or which fail to genuinely respect their physical, social, and emotional needs that are of concern. A whole array of nonaversive, noninvasive experimental observational procedures are available to teach students about animal behavior and help them appreciate, rather than exploit, animals (Riss and Goodall 1977; Lockwood 1984). Second, to suggest that students cannot learn to think and hypothesize about a phenomenon without conducting a laboratory investigation may reflect inadequacies in the way we teach students to reason. A student who understands state-of-the-science findings about nervous system functions should not need to personally lesion rats or cats in order to generate predictions about the effects of CNS injuries on behavior.

This, in turn, leads to the final contention of many animal research "traditionalists," that students somehow learn "better" with hands-on experience. If our aim as teachers is to teach well, and if we also seek to better respect animal welfare, there is a pressing need to develop, empirically test, and publish the results of teaching procedures that do not involve pain to animals or that require fewer animals than traditional approaches. For example, students could be taught about aversive classical conditioning by (1) shocking rats and observing conditioning effects, (2) watching a videotape of the same procedure, or (3) reading about, listening to classroom discussions about, and responding to programmed instruction questions about conditioning principles. These three instructional strategies range from being highly aversive to animals, to involving no pain to animal subjects. The dependent measures in a teaching method study of this kind could include an assessment of knowledge and understanding of the key principles one wants students to grasp, as well as the duration of instructional effects and the impact on students' ability to generalize their knowledge to human phenomena.

If students learn as well or better under a teaching alternative that does not cause pain to animals, practical and empirically-based 
strategies for more humane teaching can be developed. Even if students are found to learn somewhat better under the lab study, it remains the burden of psychology teachers as a professional group to demonstrate that those learning benefits clearly outweigh the costs, in pain, endured by the animal. Given the degree of public interest in animal welfare, and given the negative attention behavioral and biomedical investigators receive on this matter, solid research producing alternatives to aversive teaching procedures should prove fundable, publishable, and of wide interest to educators in psychology, medicine, veterinary medicine, biology, physiology, and other areas.

\section{The Utility of Animals as Human Analogues in Teaching Demonstrations}

Virtually all introductory psychology texts tell their readers that animals are used as subjects in studies involving procedures that cannot be ethically or easily conducted using human subjects. Shapiro (1983) has pointed out that those same textbooks rarely deal with the ethical questions that arise when animals are used. By omission, they implicitly seem to convey to students early on that "anything goes" ethically so long as a project's subjects are not human. Even beyond the matter of ethics, however, is the issue of whether teaching demonstrations with animals that are intended to approximate some human phenomenon really do justice to the phenomena we want our students to understand.

The extent to which psychologists are willing to generalize findings from animal behavior studies to human behavior (and thereby assume the validity of animal behavior analogues) depends considerably on the theoretical orientation of the psychologist. Within certain schoolsbehavior analysis, behavior therapy, and approaches stressing the biological bases of behavior, for example - the generality of behavioral principles across species is rather widely accepted. In contrast, theories which stress cognitive, dynamic, phenomenological, or humanistic variables are less likely to accept the premise that animals serve as reasonable analogues for important areas of human behavior.

A discussion of the validity of generalizing animal research findings to analogous human phenomena is beyond the scope of this chapter. The issue of generalizability depends greatly on the specific behavior in question, the history and individual makeup of the animal used in a study, artificial or unnatural constraints placed on the animal's behavior, the degree to which species-specific influences are present, the extent to which a class of behavior is mediated by cognitive or verbal factors that operate only or primarily in humans, and so on. However, with respect to demonstrations of the kind usually conducted in a psychology teaching laboratory, (1) phenomena which students observe using an aversive 
procedure with an animal are often easily understood without the demonstration; and (2) complex human phenomena can often be more directly studied by having students conduct projects with humans. Let us consider, especially, this second point.

An area of research that has been popular over the past decade concerns "learned helplessness" (Seligman 1978). This research, which evolved in the laboratory, entails highly aversive procedures such as extensive shock history to induce helplessness in experimental animals. There have now been many hundreds of animal analogue studies, student demonstrations, undergraduate honors projects, theses, and dissertations on learned helplessness, all of them intentionally creating pain and chronic, unalleviated distress for the experimental animals under study.

Interest in learned helplessness is understandable, in part because this phenomenon does appear salient for conceptualizing certain depressive disorders in humans. However, the persistence of animal studies and student laboratory teaching demonstrations of learned helplessness illustrates that an animal analogue can become extended far beyond the human construct it is intended to approximate: while there is consistency of findings among animal studies of learned helplessness, even proponents of this line of research concede that generalizing those animal findings to humans has proven difficult and inconclusive (Seligman 1978). One obvious reason for this problem is that animals represent a poor analogue for the helplessness phenomena because depression undoubtedly includes cognitive labeling processes, anticipations, cognitive expectancies, and complex affective variables that operate in humans but probably not in most other animals.

Rather than teaching students about learned helplessness by having them shock animals to induce helplessness and then observe the animals' behavior in some task that may be inhumane and further distressing (e.g., determining how long it takes a "helpless" rat to give up swimming and drown), we must develop more inventive, realistic, and valid demonstrations. There are many examples in the research literature of human paradigms to study behavioral phenomena for which we historically relied on aversive demonstrations with animals. For example, learned helplessness can be studied, not with animals, but by using task failure or frustration paradigms with human subjects; response suppression can be studied by having students develop behavioral selfmanagement contingencies to modify their own bad habits; conditioning projects can, with inventiveness, allow students to use themselves as subjects. By utilizing such experimental human paradigms, it is possible to reduce unnecessary pain to animals, produce higher quality teaching demonstrations, and allow students to better see and appreciate key behavioral/motivational principles as they occur in people. Such human 
paradigms can teach many of the same observational, experimental, and conceptual skills as the aversive animal studies they could replace.

There is little to be gained, and much to be lost, by encouraging, assigning, or even permitting students to conduct aversive procedures with animals. The vast majority of psychology students - certainly all undergraduates and virtually all graduate-level students - can be taught behavioral and experimental procedures, can be exposed to the kinds of knowledge we expect them to learn, and can hone their observational skills without ever hurting an animal, depriving an animal of its needs, or behaving inhumanely. While promoting animal welfare and student welfare in these ways will require the adoption of alternative methods of instruction at both introductory and advanced levels and will require the bucking of some traditions, it can be done. The end result will not compromise educational objectives but can produce a more sensitive and ethical professional for the future.

There is, however, a small group of advanced students who will be preparing for professional careers that specifically involve animal research. These might include graduate students in physiological psychology, animal experimental psychology, and similar areas. While graduate students in these areas represent a very small and apparently declining percentage of the total number of advanced psychology students in our universities (American Psychological Association 1985), they are an important group. By enhancing the sensitivities towards animal welfare among those students who will be the laboratory teachers and animal researchers of tomorrow, many of the insensitive or inhumane practices which exist today can be eliminated. How can we promote better sensitivity for graduate students in these specialized areas?

\section{Shaping Humaneness Among Graduate Students in Animal Experimental Psychology}

Not long ago, I conducted a small, nonrandom survey of some advanced graduate students who had done supervised laboratory work with animals, chiefly aversive conditioning and neurosurgical experiments. I asked each student if he or she had seen the APA Ethical Standards for the treatment of laboratory animals posted in the lab (American Psychological Association 1981). All had. I then asked whether these standards were ever discussed with them, or whether the students had personal discussions with their faculty supervisor concerning ethical and humane issues in dealing with animals. Other than hearing advice to "keep the cages clean, and keep the animals fed and watered," none of the students recalled any discussion about humane issues. Not one of the students reported exposure to any structured teaching on ways to minimize pain or distress in animals, and none 
had been taught the desirability of using minimal levels of shock or deprivation, methods of reducing the number of animals used in experiments, or about analgesics and their effects. Not a single student I surveyed said that she or he had any awareness of how to house animals in such a way as to meet their social, stimulation, or psychologicalemotional needs.

It was evident that these students had remarkably little exposure to ethical and humane issues even though each was engaged in projects that caused pain to laboratory animals. While the students were acquiring technical laboratory skills, there appeared to be no transmission of humane values or expertise from faculty to students. Under such circumstances, it would be indeed surprising if these students did not develop the same ethical "blind-spots" as their mentors. A national survey of ethics teaching in psychology conducted by Trautt, Reed, and Scheider (1983) suggests the students I had talked with were not unusual. Trautt et al. (1983) found that 72 percent of graduate programs in experimental psychology did not routinely train students in professional ethics, and that 83 percent had no formal procedure for students to demonstrate knowledge of ethics.

As one starts to label an advanced student as a researcher or a research assistant, as graduate students in animal behavior conduct their supervised research or theses or dissertations, the same ethical and humane responsibilities that affect a faculty member come to bear on his or her student. Unfortunately, while psychology has been quite strong in teaching students technical skills for working with animals, it has been very weak in teaching the ethical issues which arise in that research.

In a humane academic world, a faculty member would be keenly cognizant of animal welfare issues and would model, teach, and shape the same sensitivities in his or her students. Not only would humane sensitivity be encouraged, but a student would be expected to exhibit the specific skills, competencies, and knowledge necessary for treating research animals in an ethically responsible manner. Unfortunately, a number of factors operate to hinder this ideal scenario. Many experimental faculty researchers are themselves unaware of key issues in animal welfare and of new alternatives to the traditional research methods that they themselves were first taught. Some researchers react defensively to any suggestion that animals have been treated inhumanely in the past and deserve better treatment in the future. And, the same emotional desensitization and cognitive rationalization to animal pain discussed earlier in relation to students most certainly affects many faculty researchers to an even greater degree. Faculty, like most people who are invested in their work, tend to perceive (and perhaps to inflate) the potential benefits of their projects, and may unintentionally minimize or misperceive a project's limitations or even its inherent inhu- 
maneness. The contention that researchers can, and often do, overestimate the importance and underestimate the limitations of their work is certainly not restricted to researchers in animal behavior. Most journals, publishers, conferences, and funding agencies in all scientific areas rely on expert reviewers to impartially evaluate manuscripts or proposals, and rejection rates of 80 to 90 percent are common among major scientific journals. If a journal rejects 90 percent of all manuscripts, one could argue that 90 percent of the time, external judges evaluate a study's limitations to be more serious than does the study's author. If we acknowledge these factors as possibilities, the need to ensure better ethical/humane education for advanced students in animal behavior is also evident.

There are many potential vehicles for enhancing humane values and skills in graduate students who plan career work with animals. A psychology department could develop a course in animal research ethics and require the course as a prerequisite to any laboratory activities. Such a course might address not only standard animal care, but also include broader discussion of ethical issues, consideration of alternative research strategies to those which cause pain to animals, presentation of methods for meeting the social-emotional-psychological needs of various animal species, discussion not only of the benefits of a research project but also the costs in pain that might be endured by animal subjects, and related topics. For a course of this kind to be viable, it would require evenhanded input from concerned animal laboratory researchers, ethicists, scientists with a background in animal welfare and animal rights, humane advocates, ethologists, veterinarians, and others. For the course to be successful, it should provide a vehicle not just for discussion and information transmission, but should also produce change in the way animals are viewed and treated, and in the way research is conducted.

A second vehicle for decreasing animal maltreatment is an effective institutional animal care review committee. While many psychology departments and research institutions have such committees, their role and safeguarding function varies widely. Too often, animal care committees are composed of animal researchers or faculty with a vested interest in the type of projects being evaluated, rather than persons who might knowledgably and impartially evaluate proposals with an eye to safeguarding the welfare of animals. Further, while review committees ordinarily consider whether a project adheres to existing but limited statutes concerning housing, feeding, and animal procurement, committees rarely deal with other substantive ethical and humane issues. These issues include evaluating whether a project will primarily replicate previous work, result in relatively unimportant findings, utilize more animals than necessary or use a procedure that could be replaced with 
a less invasive one, subject animals to distress with little potential scientific benefit, adequately address the social-emotional well-being of the animals, or utilize a large sample statistical design that could be replaced by a sophisticated "small $n$ " design. Committees may avoid these important issues because they require making judgments and may result in dissension. However, the very purpose of a review committee is to critically review, judge, and evaluate; to the extent that a committee fails to deal with key humane issues and primarily "rubber-stamps" protocols, it also fails to perform a legitimate and necessary function.

Animal use committees should influence not only faculty researchers, but also graduate students in animal behavior. Training ethical researchers requires that students learn to anticipate and address humane issues while a study proposal is being developed. A properly-constituted, stringent, questioning review committee can help to establish contingencies that will shape more ethical and humane treatment of animals in teaching settings.

Finally, individual faculty must broaden their teaching functions to explicitly instruct students in humane issues. The role of a professional mentor is an important one for influencing the values, practices, and sensitivities of students, especially at a doctoral training level. To the extent that faculty researchers are themselves sensitized to animal welfare issues, they will be better able to transmit those sensitivities to their students. Reese (1984), for example, has developed a detailed questionnaire that must be completed by students before they can initiate any project using animals. The questionnaire requires the student to state how animal care needs, broadly defined, will be met; whether animals will suffer any distress; what will be done to prevent or eliminate that distress; how the number of animals to be studied can be reduced; and which alternative, noninvasive methodologies can be employed. Discussion of these issues by a student and a faculty member will not automatically ensure that animal welfare needs will be met unless there is also a strong commitment to improving humane treatment of animals and a willingness to alter research paradigms to promote it. On the other hand, it is very unlikely students can be ethically sensitized without discussion and guidance of the kind advocated by Reese (1984).

\section{Teaching Students in Psychology: A Curriculum Sensitive to Animal Welfare}

Let us summarize and review how a psychology teaching program that is humane towards animals might look and how instructional change can be accomplished. The first step in bringing about animal welfare 
reform is for a department to critically assess the number and kinds of animals employed in teaching and instructional/student research projects; the courses or projects in which animals are used; the reasons animals are used in those courses and projects (e.g., to have students learn behavioral principles by conditioning rats); and the invasiveness or severity of procedures to which animals are subjected. With respect to this latter issue, Shapiro (1984) has pointed out the need to develop a reasonable, workable system for estimating the pain level or aversiveness to animals of various laboratory procedures. At present, there is no widely-used invasiveness rating scale, although one has been described (see Ross 1981) and is being used in Australia. By estimating empirically levels of invasiveness or pain, it will be possible to estimate the relative distress caused by different procedures. For example,an observational study of animals in a naturalistic environment suitable for that species would likely be considered noninvasive or, say, a " 1 " on a 10-point severity scale. Projects that entail the use of aversive stimuli, severe deprivation, surgery, drugs, and other invasive procedures would be rated higher on the severity scale. By classifying procedures in this way, it will be possible to direct attention on developing alternatives to those procedures, altering procedures to reduce their invasiveness, or requiring stronger justification for their use.

A second step towards developing a more humane curriculum is establishing strictures on various practices and, concomitantly, developing instructional alternatives to replace unacceptable procedures. For example, a department might establish a policy that students will not conduct projects, and faculty will not perform demonstrations, that entail shock, surgery, or severe deprivation to animals in undergraduate courses or in most graduate courses. (As noted earlier, there is a need for better objective guidelines concerning both the invasiveness of laboratory procedures and the point at which deprivation of food, water, sleep, or stimulation needs becomes inhumane.) It would rest with the individual or collective faculty to develop alternative methods to teach students the principles about which they would have learned from the demonstration. Here, reading or classroom discussions; the use of computer-assisted or audio-visual materials; a demonstration not creating distress for animals; or some other human experiential project could be used as instructional alternatives.

Third, explicit policies and more effective safeguarding mechanisms can be developed to address those relatively specific occasions when aversive procedures with animals are justified. Such occasions might be theses or dissertations by students specializing in areas of psychology such as animal learning and physiological psychology, or student assistance on a faculty member's research. Several safeguarding mechanisms (including a course in animal welfare and research ethics, review committee 
scrutiny, and justification/invasiveness reduction planning) have already been discussed. Others, including ongoing review committee monitoring of faculty research, can promote more humane treatment of animals by both faculty members and students. Departments that take seriously the mandate for improved animal welfare could establish contingencies and provide academic recognition for faculty and students who develop and implement research and teaching alternatives that reduce the number of animals used, reduce the aversiveness of laboratory procedures, or replace the use of living animals altogether in various studies.

Finally, the conditions under which animals are maintained merit attention in the humanely-sensitized psychology department. Faculty and students who work with animals have an obligation to become familiar with their preferences for social contact with other animals, the environmental stimulation, and the habitat conditions needed-or enjoyed - by any animals maintained in a laboratory vivarium. The practice of housing animals in a manner that is convenient and inexpensive for humans, but distressingly barren for the animals, is ethically unacceptable to psychologists concerned with animal welfare. Several researchers have described the creation of naturalistic, environmentallyenriched housing settings for laboratory animals (Reese 1984; Segal 1983), and there are ample sources of information concerning animals' habitat preferences both in the ethology literature and through consultation with national humane organizations.

The focus of this paper has been the teaching of students in psychology. However, similar problems for animal welfare exist in the way we have traditionally taught medical students, veterinary students, and students in other behavioral/biological sciences. In each of these areas, animals often endure painful, invasive procedures solely for the purpose of showing students some already well-known phenomenon.

The alternatives we have discussed throughout the paper apply not only to teaching psychology students, but to teaching students in these other areas as well. For example, many traditional instructional practices using animals in medical education - having students observe physiological effects, observe toxicity effects, and "practice" surgery on animals - could be replaced by alternative teaching methods that would eliminate the use of living animals in some cases or greatly reduce the number of animals subjected to unnecessary pain in other cases (Branch et al. 1984). The benefits of exploring and implementing teaching alternatives in medical, veterinary, and biological science education are the same as those discussed earlier; animal welfare would be improved and student ethical/humane sensitivities would remain intact rather than be deadened. In addition, the more practical issues of cost and public image are increasingly salient. As communities and states enact legislation 
reducing the availability of cheap pound-seized animals, and as the public becomes aware of unnecessary, inhumane use of animals, there is a further impetus to develop new ways of teaching. While some would argue that living animals must be subjected to distress in order to train physicians, veterinarians, and others, this contention is questionable and probably reflects American tradition rather than educational necessity. In Great Britain,for example, nontherapeutic procedures are rarely performed on living animals during the training of veterinary students (Rollin 1981).

\section{Summary and Conclusions}

The treatment of animals within educational, research, and training institutions has received growing scrutiny both by the public and by scientists concerned with animal welfare. As in many "movements," we have seen to date a strong tendency to polarize issues involving animal welfare into extreme positions. Some animal rights proponents argue against the use of animals for any scientific purpose; scientists, on the other hand, often defend the status quo of animal experimentation and deny the existence of fundamental ethical issues arising from it. Yet, from these polarized viewpoints can come the potential for dialogue that will result in both better science and the more humane treatment of animals. Recent symposia on animal welfare at major scientific meetings are a sign, tentative but promising, that the treatment of laboratory and research animals is beginning to change.

Change is possible quite quickly in the way animals have been used as "teaching tools" for students in psychology and in other academic areas. Technologies and educational alternatives already exist which, if used creatively, can eliminate the tradition of hurting, distressing, and maiming animals for the purpose of showing students behavioral phenomena. In those few instances when advanced students in a specialty area must use invasive procedures-and these instances should be rare - we can have available safeguards to better ensure animal welfare, to decrease the level of aversive procedures that are employed, and to greatly reduce the number of animals subjected to distress. Throughout this paper, such alternatives and protective mechanisms have been discussed.

The mandate to improve animal welfare in the teaching setting will require changing practices that have become traditional and longstanding. Retrospective justifications ("We have always done this with animals and it has led to great advances..."), as Shapiro (1984) has pointed out, do not tell us that a particular practice was the only one available, that it was the best practice, or that it should be continued 
in the future. Rather than defending the historical status quo, behavioral scientists and educators should take the lead in developing and evaluating new humane teaching and animal protective alternatives.

If successful, alternatives like those discussed here should produce clear, measurable effects. In a humanely-sensitized educational program, the frequency of procedures that could be considered aversive will be substantially reduced in all courses and independent study projects. As teaching alternatives replace many "live animal" demonstrations, the number of animals being secured will decrease. Course requirements in animal welfare and animal research ethics will appear in departmental course listings. Animal care committees, rather than approving proposals almost carte blanche and evaluating them based on the usual narrow criteria of cage space and food, will be broad-based in composition and will assume an active animal welfare advocacy role. Committees will require study modifications and statistical changes to reduce the number of animals used; will decrease the use of aversive procedures; and will reject proposals lacking sufficient merit, creating excessive distress for animals, or using procedures that are inherently objectionable. In a humanely sensitized department, animal housing facilities will look different. If fewer animals are being used, fewer will need to be housed; those that are housed will live under carefully-created conditions that very much resemble the animals' preferred habitats and meet their social-emotional, as well as physical, needs. The point here is that improvement in the treatment of animals in teaching settings will ultimately be reflected not just in talk about animal welfare, but by actual, visible, measurable change along dimensions such as these.

To a large extent, initial pressures for reform in the way that animals are treated in behavioral and biomedical areas have come from humane, animal welfare, and animal rights groups outside the scientific community. ${ }^{*}$ However, for change of the kind discussed here to take place, it will be necessary for those of us in the academic community to explicitly recognize an obligation not only to teach and conduct research, but also to create conditions that ensure better animal welfare than is the case presently. By developing, examining, and implementing new teaching approaches that do not cause pain for animals, we will be in a position to teach students just as scientifically as always, but more humanely as well.

While most pressure for humane reform has arisen outside the scientific community, animal welfare groups within various professions also exist and have advocated reform. These groups include Psychologists for the Ethical Treatment of Animals (PsyETA), the Scientists Center for Animal Welfare (SCAW), the Animal Legal Defense Fund and others. 


\section{Acknowledgments}

The author extends appreciation to Felicia Ford for her research assistance, and to Jane Peters, Janet S. St. Lawrence, Evelyn Segal, and Kenneth Shapiro for their comments concerning an early draft of this paper. 


\section{References}

American Psychological Association. 1981. Ethical principles of psychologists. American Psychologist. 36:633-8.

American Psychological Association. 1985. Unpublished data reporting on the results survey of admissions to experimental psychology doctoral programs in the United States.

Branch, C.E., Robertson, B.T., Smith, E.P. and Vaughan, J.T. May, 1984. Interactive video in veterinary medical education: An alternative to live animal experimentation. In: Proceedings, American Veterinary Computer Society, College of Veterinary Medicine, Mississippi State University, Second Symposium on Computer Application. pp. 219-22.

Janis, I.L. and Mann, L. 1977. Decision-making: A Psychological Analysis of Conflict, Choice, and Commitment. New York: Free Press.

Lockwood, R. August, 1984. Kindness is creative. Presentation to Psychologists for the Ethical Treatment of Animals. American Psychological Association Annual Meeting. Toronto.

Maddison, D.C. 1978. What's wrong with medical education? Journal of Medical Education. 12:97-102.

Milgram, S. 1963. Behavioral study of obedience. Journal of Abnormal Social Psychology. $67: 371-8$

Reese, E.P. August, 1984. Teaching sensitivity to animal welfare will make students better scientists. In: Bernstein, E. (Chair). Ways to minimize pain and suffering for laboratory animals. Symposium at American Psychological Association Annual Meeting. Toronto.

Riss, D. and Goodall, J. 1977. The recent rise to the alpha rank in a population of free-living chimpanzees. Folio Primatol. (Basel), 27:134-51.

Rollin, B.E. 1981. Animal Rights and Human Morality. Buffalo, NY: Prometheus Books.

Ross, M. 1981. The ethics of experiments on higher animals. Social Science in Medicine. 13(F):51-60.

Russell, W.M.S. and Burch, R.L. 1959. The Principles of Humane Experimental Technique. London: Methuen.

Segal, E. 1982. Editorial. Journal of Experimental Analysis of Behavior. 38:115.

Segal, E. August, 1983. Discussant comments. In: King, F.A. (Chair). Use of primates in behavioral and biomedical research. Symposium presented to the American Psychological Association. Anaheim, CA.

Seligman, M.E. 1978. Learned helplessness as a model of depression: Comment and integration. Journal of Abnormal Psychology. 87:165-79.

Shapiro, K. 1983. Personal communication reporting on an informal survey of 25 introductory psychology textbooks.

Shapiro, K. May, 1984. Cost-benefit analysis: Critique and complements. Paper presented to the Association for Behavior Analysis Annual Meeting. Nashville.

Thomas, M.H., Horton, R.W., Lippincott, E.L., and Drabman, R.S. 1977. Desensitization to real-life aggression as a function of exposure to television violence. Journal of Personality and Social Psychology. 35:450.

Trautt, G.M., Reed, J.G. and Schneider, J.A. 1983. Teaching of ethics in psychology: Results of a national survey. Paper presented to the Eastern Psychological Association Annual Meeting.

Truax, C.B., Wargo, D.G., Frank, J.D., Imber, S.D., Battle, C.C., Hoehn-Saric, R., Nash, E.H., and Stone, A.R. 1966. Therapist empathy, genuineness, and warmth and patient therapeutic outcome. Journal of Consulting Psychology. 22:331-4. 